\title{
A comparative study on handover probability analysis for future HetNets
}

\author{
S. Neeraja, A. Abhishiktha \\ Department of Electronics and Communication Engineering, GITAM (Deemed to be University), India
}

\begin{tabular}{l}
\hline \hline Article Info \\
\hline Article history: \\
Received Nov 8, 2018 \\
Revised Jul 10, 2019 \\
Accepted Jul 17, 2019 \\
\hline
\end{tabular}

\section{Keywords:}

Handoff/handover

Handover probability

HetNet

\begin{abstract}
The need of wireless services increasing day by day due to the advancements in the field of wireless technology towards $5 \mathrm{G}$ for instant transferring the mails, messages and video calling without any interruption. In LTE and 5G wireless networks, major task is to provide seamless connection anywhere, anytime when the user may roam among Heterogeneous Wireless Networks (HetNets). To achieve proper mobility management among HetNets, handoff or hadover is required. Handover Probability is one of the metric to estimate the handover performance, which is a probability of Mobile Node to handover the present connection from the current base station to another base station or enode B. In this paper, handoff probability analysis is done for multiple HetNets based on Handover Algorithm. To estimate this algorithm, bandwidth is considered as one of the key parameter. A comparative analysis of handover probability for two, three, four and five HetNets has been performed. The results can demonstrate that the variation of handover probability with respect to traffic load, threshold and bandwidth. It is observed that, as the number of wireless networks increases handover probability slightly increases with traffic load. These results are more significant to estimate further wrong decision handovers based on that Quality of Service (QoS) is evaluated in practical HetNets such as integration of LTE, Wi-Fi and WiMAX etc.
\end{abstract}

Copyright (C) 2019 Institute of Advanced Engineering and Science. All rights reserved.

\section{Corresponding Author:}

\section{S. Neeraja,}

Department of Electronics and Communication Engineering,

GITAM (Deemed to be University),

Gandhi Nagar, Rushikonda, Visakhapatnam, Andhra Pradesh, Pincode: 530045, India.

Email: gitamneeraja@gmail.com

\section{INTRODUCTION}

The advancements in Wireless and Mobile Communication technologies are drastically moving towards the fifth generation $(5 \mathrm{G})$ cellular systems. With the technology advancements, the future generation wireless networks will integrate the current wireless networks such as LTE, WiMAX, WLAN, and Wi-Fi etc. to allow the user to provide anywhere, anytime best communication services. The combination of different wireless networks with different access technologies are termed as heterogeneous wireless networks (HetNets). Consequently, the Mobile Nodes (MN's) always select the best available network for access, called the "always best connected" network [1,2]. The multiple MN's with multiple interfaces will able to choose the best link among all available candidates. Handover or handoff is a process which seamlessly transfer the ongoing conversation from one network to another network without interruption in order to support the high mobility and to provide the QoS to the end users during communication. Handoffs can be divided into two types: 1) a handover that occur between the similar types of networks is called a Horizontal Handoff e.g. LTE to LTE and 2) a handover handoff that occur between dissimilar types of networks is called a Vertical Handoff [3] e.g. LTE to WiMAX. Vertical Handoff helps MN to select the best network among HetNets for providing desired 
QoS. An accurate handoff algorithm design is major goal of a network designer in order to ensure MN's can maintain an acceptable QoS.

In the literature, most of the handoff algorithms are designed between similar networks which are based on Received Signal Strength (RSS) e.g GSM to GSM or CDMA to CDMA [4, 5]. Various vertical handoff algorithms are observed and designed based on area of application and user requirements [6]. RSS-based vertical handoff algorithm is relatively mature and easy to realize, however, the lack of comprehensive consideration of different network parameters and end user requirements limits its performance and application in heterogeneous environment. Other than RSS based, various vertical handoff algorithms are presented based on Signal to Interference Noise Ratio [7], cost function and additive weighting function etc.

In designing cost function based vertical handoff algorithm [8], multiple system performance parameters and end- user characteristics are taken into account, therefore, the algorithm performs better than conventional RSS based handoff algorithm. The drawback of this algorithm is the lack of adaptation capability for once defined, the form of the cost function is fixed for all the users and for all the service types, hence, it is difficult to adapt the algorithm based on different user requirements, especially for different service traffics.

In additive weighting based vertical handoff algorithm [9], parameters affecting handoff performance are chosen as decision factors such as threshold, end to end delay etc. Different factors are assigned different weights which could be dynamically adjusted according to network state and various user services, therefore, it is possible to guarantee different user QoS requirement and improve the performance of the whole network meanwhile.

Handoff algorithms based on the RSS does not meet the requirement of upper layer applications where traffic is more and sensitive with time so handoff is implemented based on the bandwidth as the main parameter. Handoff algorithm based on bandwidth for two and three heterogeneous wireless networks are available in the literature [10], [11]. In this paper, Probability of handoff analysis is done for multiple HetNets (two, three, four and five) based on handover algorithm by considering bandwidth as $20 \mathrm{MHz}$ which is suitable for evaluating the performance of current wireless HetNets such as integration of LTE and WiMAX, LTE to $\mathrm{Wi}-\mathrm{Fi}$ etc. From the results, the handover probability comparative analysis is carried out for multiple (two, three, four and five) HetNets.

\section{ANALYSIS OF PROBABILITY OF HANDOVER}

Probability of handover is the probability of $\mathrm{MN}$ is moving out of its existing network. Consider five networks N1, N2, N3, N4 and N5. Analytical models for Handover are designed for these networks using Markov Model as shown in Figure 1. Here,

$\mathrm{C}_{\mathrm{Nj} / \mathrm{Ni}}(\mathrm{t})$ : $\mathrm{MN}$ is changing from network $\mathrm{Ni}$ to network $\mathrm{Nj}$ at time $\mathrm{t}$.

$\mathrm{S}_{\mathrm{Ni}}(\mathrm{t})$ : MN continues at current network $\mathrm{Ni}$ at time $\mathrm{t}$

$\mathrm{P}_{\mathrm{Nj} / \mathrm{Ni}}$ : Probability of $\mathrm{MN}$ transferring from network Ni to network $\mathrm{Nj}$ at time $\mathrm{t}$

$\mathrm{P}_{\mathrm{Ni} / \mathrm{Ni}}$ : Probability of MN continuing at network $\mathrm{Ni}$ at time $\mathrm{t}$

The change in bandwidth procedure of network $\mathrm{i}, \mathrm{i}=\mathrm{N}$ (where $\mathrm{N}$ is the no of networks) is developed as an $\mathrm{M} / \mathrm{M} / \mathrm{Bi}$ process [11]. Where $\mathrm{Bi}$, the maximum bandwidth and bi is the available bandwidth of the network. The arrival rate of requirement for channels is denoted with a Poisson distribution with parameter $\delta_{\mathrm{i}}, i=N$. and the service rate, at which the channel is cleared, will obey an exponential distribution with parameter $\boldsymbol{\eta}_{\mathbf{i}}, i=N . \boldsymbol{\alpha}_{\mathrm{i}, \mathrm{y}}, i=N . \mathrm{y}=0,1, \ldots . \mathrm{Bi}$ Constitute the probability of occupied channels is $\mathrm{y}$. From queuing theory result, the following equations hold

$$
\begin{gathered}
\eta_{\mathrm{i}, \mathrm{y}}=\mathrm{y} \eta_{\mathrm{i}}, \mathrm{y} \leq \mathrm{Bi} \\
=0, \text { otherwise } \\
\alpha_{\mathrm{i}, \mathrm{y}}=\alpha_{\mathrm{i}, 0} \beta_{\mathrm{i}}^{\mathrm{y}} / \mathrm{y} !, 0<\mathrm{y} \leq \mathrm{Bi}
\end{gathered}
$$

where $\beta$ is traffic load.

$$
\alpha_{i, 0}=\frac{1}{\sum_{y=0}^{B i} \beta_{i}^{y} / y !}, i=1,2,3,4,5
$$


The analytical model of handover for two wireless networks as shown in Figure. 1 (a) is explained by C. Chi, et.al. [10]. Consider, the probability of handover for three networks i.e. Figure. 1 (b). In order to find the MN moving between different nodes by using three state Markov design and the variables $\mathrm{p}, \mathrm{q}$ represent the probability of $\mathrm{MN}$ switching from $\mathrm{N} 1$ to $\mathrm{N} 2$ and from $\mathrm{N} 2$ to $\mathrm{N} 1$. Variables $\mathrm{s}$ and $\mathrm{r}$ represent the probability of $\mathrm{MN}$ moving from $\mathrm{N} 3$ to $\mathrm{N} 2$ and $\mathrm{N} 2$ to $\mathrm{N} 3$ and the variables $\mathrm{u}$ and t represent the probability of MN shifting from $\mathrm{N} 1$ to $\mathrm{N} 3$ and $\mathrm{N} 3$ to $\mathrm{N} 1$. The probabilities (1-p-u), (1-q-r) and (1-s-t) represent the probability of $\mathrm{MN}$ stay at $\mathrm{N} 1, \mathrm{~N} 2$ and $\mathrm{N} 3$ are represented by $\mathrm{P}_{\mathrm{N} 1}, \mathrm{P}_{\mathrm{N} 2}$ and $\mathrm{P}_{\mathrm{N} 3}$.

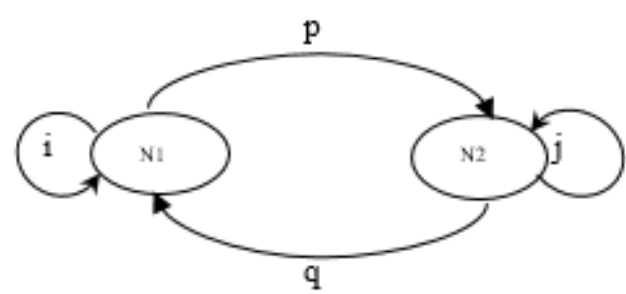

(a)

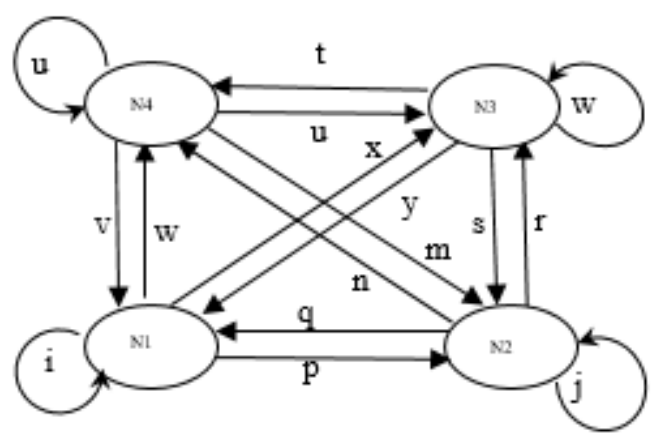

(c)

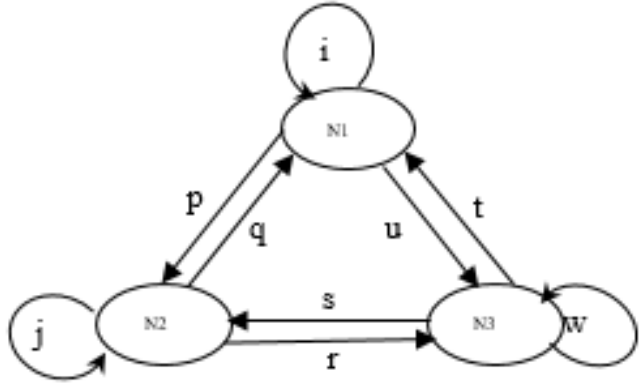

(b)

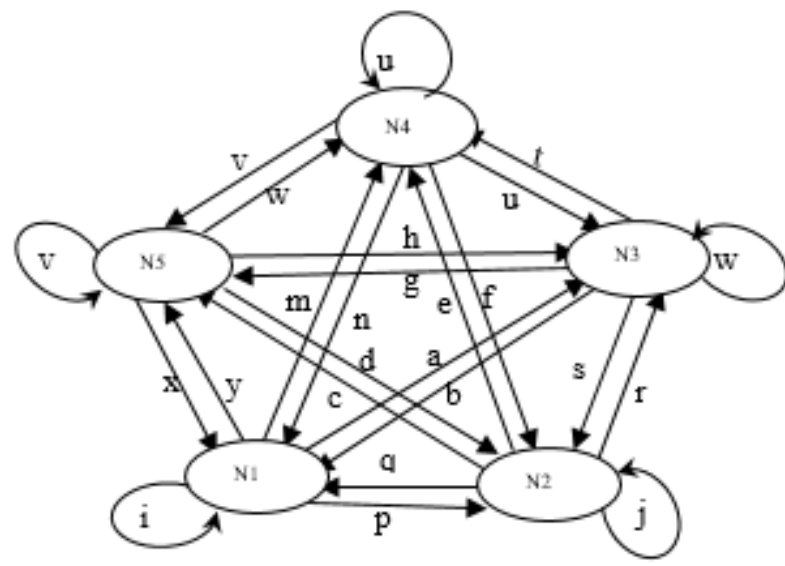

(d)

Figure 1. Analytical models for handover between heterogeneous wireless networks,

(a) Markov Model for two wireless networks, (b) Markov Model for three wireless networks,

(c) Markov Model for four wireless networks, (d) Markov Model for five wireless networks

Algorithm: Probability of Handover Algorithm based on Bandwidth

Let available bandwidth of network b1, b2, b3 and threshold $\mathrm{G}_{\mathrm{th}}$.

If a $\mathrm{MN}$ is at $\mathrm{N} 1$ then

If $\mathrm{b} 2-\mathrm{b} 1 \geq \mathrm{G}_{\mathrm{th}}$, the $\mathrm{MN}$ moves to $\mathrm{N} 2$

Otherwise stays at N1.

Else if a $\mathrm{MN}$ is at $\mathrm{N} 1$ then

If $\mathrm{b} 3-\mathrm{b} 1 \geq \mathrm{G}_{\mathrm{th}}$, the MN moves to N3

Otherwise stays at N1.

Similarly, for a MN is at $\mathrm{N} 2$ and N3.

\subsection{Mathematical calculations of MN staying and moving probabilities:}

Consider, three wireless networks as shown in Figure. 1 (b). The probability of mobile node staying at $\mathrm{N} 1$ is calculated as,

$$
\mathrm{P}_{\mathrm{N} 1}=\mathrm{P}_{\mathrm{N} / \mathrm{N} 2}+\mathrm{P}_{\mathrm{N} 1 / \mathrm{N} 3} / \mathrm{P}_{\mathrm{N} / / \mathrm{N} 2}+\mathrm{P}_{\mathrm{N} 2 / \mathrm{N} 1}+\mathrm{P}_{\mathrm{N} / \mathrm{N} 3}+\mathrm{P}_{\mathrm{N} 3 / \mathrm{N} 1}
$$




$$
P_{N 1}=q+t / p+q+t+u
$$

Similarly, for N2 MN staying at N2 is

$$
\mathrm{P}_{\mathrm{N} 2}=\mathrm{p}+\mathrm{s} / \mathrm{p}+\mathrm{q}+\mathrm{s}+\mathrm{r}
$$

MN staying at N3 is

$$
\mathrm{PN} 3=\mathrm{r}+\mathrm{u} / \mathrm{r}+\mathrm{u}+\mathrm{s}+\mathrm{t}
$$

The MN moves from its present network when the bandwidth of the current network is less than the other networks bandwidth at threshold $\mathrm{G}_{\mathrm{th}}$. For each network bandwidth changes dynamically so consider the network stable state such that handover does not affected by the time period $t$.

$\mathrm{MN}$ moving from N2 to N1 is

$$
\mathrm{PN} 1 / \mathrm{N} 2=\mathrm{P}\left\{\mathrm{b} 1-\mathrm{b} 2 \mathrm{G}_{\mathrm{th}}\right\}
$$

MN moving from $\mathrm{N} 1$ to $\mathrm{N} 2$ is

$$
\mathrm{PN} 2 / \mathrm{N} 1=\mathrm{P}\left\{\mathrm{b} 2-\mathrm{b} 1 \geq \mathrm{G}_{\mathrm{th}}\right\}
$$

MN moving from N3 to N1 is

$$
\mathrm{PN} 1 / \mathrm{N} 3=\mathrm{P}\left\{\mathrm{b} 1-\mathrm{b} 3 \mathrm{G}_{\mathrm{th}}\right\}
$$

MN moving from N1 to N3 is

$$
\mathrm{PN} 3 / \mathrm{N} 1=\mathrm{P}\left\{\mathrm{b} 3-\mathrm{b} 1 \geq \mathrm{G}_{\mathrm{th}}\right\}
$$

MN moving from N2 to N3 is

$$
\mathrm{PN} 3 / \mathrm{N} 2=\mathrm{P}\left\{\mathrm{b} 3-\mathrm{b} 2 \mathrm{G}_{\mathrm{th}}\right\}
$$

$\mathrm{MN}$ moving from N3 to N2 is

$$
\mathrm{PN}_{2} / \mathrm{N} 3=\mathrm{P}\left\{\mathrm{b} 2-\mathrm{b} 3 \mathrm{G}_{\mathrm{th}}\right\}
$$

MN staying at $\mathrm{N} 1$ is

$$
\mathrm{P}_{\mathrm{N} 1} / \mathrm{N1}=1-\mathrm{p}-\mathrm{u}=1-\mathrm{P}_{\mathrm{N} 2} / \mathrm{N1}-\mathrm{P}_{\mathrm{N}} / \mathrm{N} 1
$$

MN staying at N2 is

$$
\mathrm{P}_{\mathrm{N} 2 / \mathrm{N} 2}=1-\mathrm{q}-\mathrm{r}=1-\mathrm{PN}_{\mathrm{N}} / \mathrm{N} 2-\mathrm{P}_{\mathrm{N}} / \mathrm{N} 2
$$

MN staying at $\mathrm{N} 3$ is

$$
\mathrm{PN}_{3} / \mathrm{N} 3=1-\mathrm{s}-\mathrm{t}=1-\mathrm{P}_{\mathrm{N} 1} / \mathrm{N} 3-\mathrm{P}_{\mathrm{N}} / \mathrm{N} 3
$$




$$
\mathrm{P}\left\{\mathrm{bi} \geq \mathrm{G}_{\text {th }}\right\}=\sum_{\mathrm{y}=0}^{\mathrm{Bi}-\mathrm{G}_{\text {th }}} \alpha_{\mathrm{i}, \mathrm{y}} \mathrm{i}=1,2,3
$$

With independent assumptions of b1, b2, b3 we have

$$
P N i / N j=P\left\{b i-b j \geq G_{t h}\right\}=\sum_{i=0}^{B i} \sum_{\substack{j=0, i \neq j \\ i-j \geq G_{t h}}}^{B j} \alpha_{i, B i-j} \alpha_{j, B j-i}
$$

where $\mathrm{i} \neq \mathrm{j}, \mathrm{i}=\mathrm{j}=1,2,3$.

\subsection{Probability of handover calculation}

Assume, maximum bandwidth of the networks B1=B2=B3=B and Traffic load for three networks is assigned as, $\beta_{1}=\beta_{2}=\beta_{3}=\beta$.

Therefore, $\mathrm{P}_{\mathrm{N} i / \mathrm{Nj}}=\mathrm{Q}, \mathrm{i} \neq \mathrm{j}, \mathrm{i}=\mathrm{j}=1,2,3$.

Probability of handover is,

$\mathrm{PH}=\mathrm{P}_{\mathrm{N} 1}\left(\mathrm{P}_{\mathrm{N}} 2 / \mathrm{N} 1\right)+\mathrm{P}_{\mathrm{N}}\left(\mathrm{P}_{\mathrm{N}} 1 / \mathrm{N} 2\right)+\mathrm{P}_{\mathrm{N}}\left(\mathrm{P}_{\mathrm{N}} 1 / \mathrm{N} 3\right)+\mathrm{P}_{\mathrm{N} 1}\left(\mathrm{P}_{\mathrm{N}} / / \mathrm{N} 1\right)+\mathrm{P}_{\mathrm{N}}\left(\mathrm{P}_{\mathrm{N}} 3 / \mathrm{N} 2\right)+\mathrm{P}_{\mathrm{N}}\left(\mathrm{P}_{\mathrm{N}} / / \mathrm{N} 3\right)=3 * \mathrm{Q}$

The above procedure is repeated for developing probability of handover algorithm for four and five networks which are shown in Figure 1(c) and Figure 1(d). For example, consider multiple networks (N=5), then the corresponding moving and staying probabilities of the $\mathrm{MN}$ are calculated as,

Moving Probability of MN from Current Network to neighboring networks is,

$$
\mathrm{P}_{\mathrm{Ni} / \mathrm{Nj}}=\mathrm{P}\left\{b i-b j \geq G_{\mathrm{th}}\right\}, \text { for }(\mathrm{i} \neq \mathrm{j})
$$

With independent assumptions of $\mathrm{b} 1, \mathrm{~b} 2, \mathrm{~b} 3, \mathrm{~b} 4, \mathrm{~b} 5$ then,

$$
P_{N i} / N j=P\left\{b i-b j \geq G_{t h}\right\}=\sum_{\substack { i=0 \\
\begin{subarray}{c}{j=0, i \neq j \\
i-j \geq G_{t h}{ i = 0 \\
\begin{subarray} { c } { j = 0 , i \neq j \\
i - j \geq G _ { t h } } }\end{subarray}}^{B j} \alpha_{i, B i-j} \alpha_{j, B j-i}
$$

for $(i \neq j), i=j=1,2,3,4,5$

The staying Probabilities of the MN is calculated as,

$$
\begin{aligned}
& P_{\mathrm{Ni} / \mathrm{Ni}}=1-P_{\mathrm{Nj} / \mathrm{Ni}} \text { for }(i \neq j), i=j=1,2,3,4,5 \\
& P_{\mathrm{Nj} / \mathrm{Nj}}=1-P_{\mathrm{Ni} / \mathrm{Nj}}, \quad \text { for }(\mathrm{i} \neq \mathrm{j}), \mathrm{i}=\mathrm{j}=1,2,3,4,5
\end{aligned}
$$

Similarly, assume, Bandwidth $=\mathrm{B} 1=\mathrm{B} 2=\mathrm{B} 3=\mathrm{B} 4=\mathrm{B} 5=\mathrm{B}$.

Traffic Load of five networks is assumed as, $\beta_{1}=\beta_{2}=\beta_{3}=\beta_{4}=\beta_{5}=\beta$.

Then,

$$
\begin{aligned}
& P_{\mathrm{Ni} / \mathrm{Nj}}=\mathrm{Q}, \mathrm{i} \neq \mathbf{j}, \mathbf{i}=\mathbf{j}=1,2,3,4,5 \\
& \mathrm{PH}=\sum_{\substack{\mathrm{i}=1 \mathrm{j}=1 \\
\mathrm{i} \neq \mathrm{j}}}^{\mathrm{N}} \mathrm{P}_{\mathrm{Ni}}\left(\mathrm{P}_{\mathrm{Nj} / \mathrm{Ni}}\right), \quad \mathrm{i}=\mathrm{j}=1,2,3,4,5
\end{aligned}
$$

From (22), the Probability of Handover (PH) for two, three, four and five Het Nets are calculated.

For two networks, Probability of handover $=\mathrm{PH}=\mathrm{Q}$

Three networks, probability of handover $=\mathrm{PH}=3^{*} \mathrm{Q}$

Four networks, probability of handover $=\mathrm{PH}=6 * \mathrm{Q}$

Five networks, Probability of handover $=\mathrm{PH}=10 * \mathrm{Q}$ 


\section{RESULTS AND ANALYSIS}

The probability of handover (PH) analysis for multiple (two, three, four and five) HetNets has been carried out in terms of traffic load, threshold and bandwidth.

\subsection{Probability of handover vs traffic load}

Figure 2 and Table 1 represents the variation of probability of handover with respect to traffic load for different threshold values, here the bandwidth is fixed at 20MHz. For five networks for a fixed threshold $\left(\mathrm{G}_{\mathrm{th}}\right)=11$, at the traffic load $(\beta)=1$, the probability of handover is 0.81272178 and at the traffic load $(\beta)=8$, the probability of handover is 0.92249197 . It is noticed that similarly for two, three and four networks, at fixed threshold value, the probability of handover slightly increases with increase in traffic load.

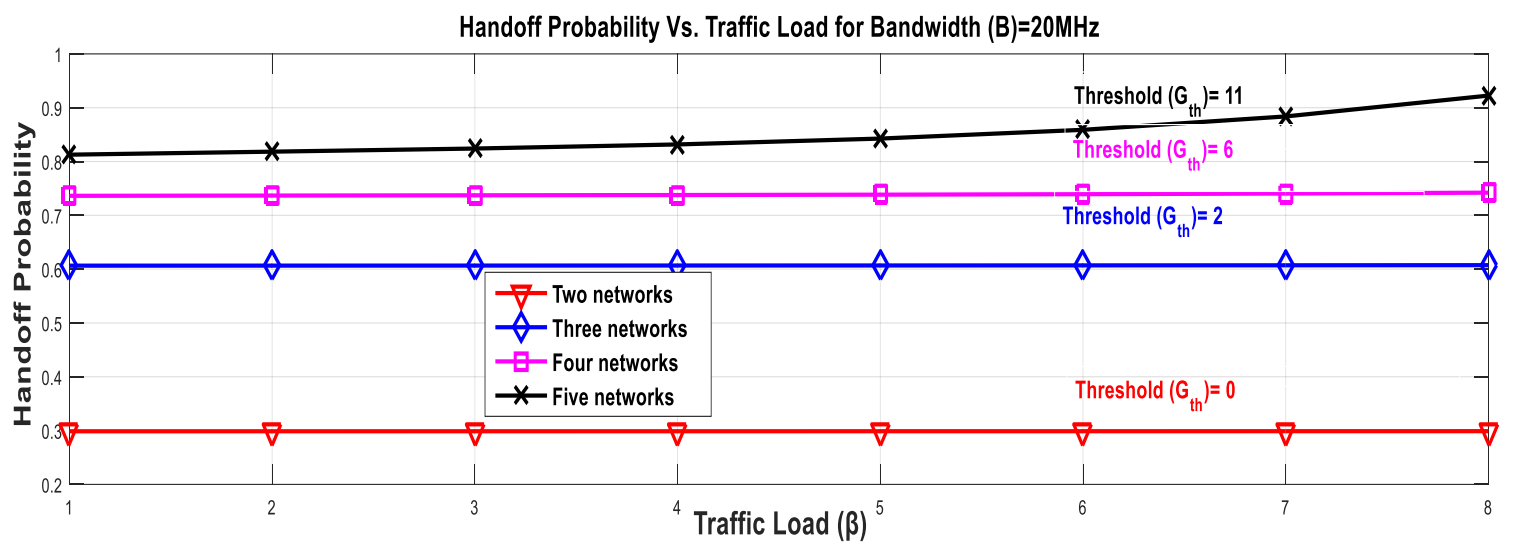

Figure 2. Probability of handover (PH) vs traffic load $(\beta)$ for different thresholds and different networks at bandwidth $(\mathrm{B})=20 \mathrm{MHz}$

Table 1. Probability of handover (PH) vs traffic load $(\beta)$ for different thresholds

\begin{tabular}{cccccc}
\multicolumn{7}{c}{ and different networks at bandwidth $(\mathrm{B})=20 \mathrm{MHz}$} \\
\hline S.No. & $\begin{array}{c}\text { Traffic load } \\
(\boldsymbol{\beta})\end{array}$ & $\begin{array}{c}\text { For two networks at } \\
\mathrm{G}_{\mathrm{th}}=0, \text { Probability } \\
\text { of handover }(\mathrm{PH})\end{array}$ & $\begin{array}{c}\text { For three networks } \\
\text { Probability of handover } \\
(\mathrm{PH}) \text { at } \mathrm{G}_{\mathrm{th}}=2\end{array}$ & $\begin{array}{c}\text { For four networks } \\
\text { Probability of handover } \\
(\mathrm{PH}) \text { at } \mathrm{G}_{\mathrm{th}}=6\end{array}$ & $\begin{array}{c}\text { For five networks } \\
\text { Probability of handover } \\
(\mathrm{PH}) \text { at } \mathrm{G}_{\mathrm{th}}=11\end{array}$ \\
\hline 1 & 1 & 0.29872073 & 0.60646194 & 0.73626923 & 0.81272178 \\
2 & 2 & 0.29874098 & 0.60655165 & 0.73674545 & 0.81830937 \\
3 & 3 & 0.29875935 & 0.60663403 & 0.73719918 & 0.82409977 \\
4 & 4 & 0.29877965 & 0.60672647 & 0.73773286 & 0.83171005 \\
5 & 5 & 0.29880370 & 0.60683798 & 0.73841081 & 0.84262244 \\
6 & 6 & 0.29883310 & 0.60697676 & 0.73930181 & 0.85890354 \\
7 & 7 & 0.29886956 & 0.60715222 & 0.74049432 & 0.88377219 \\
8 & 8 & 0.29891523 & 0.60737626 & 0.74211066 & 0.92249197 \\
\hline
\end{tabular}

\subsection{Probability of handover vs threshold}

Figure 3 and Table 2 represents the variation of probability of handover with respect to threshold for different traffic load values and for different networks, here the bandwidth is fixed at $20 \mathrm{MHz}$. As the number of networks increases, the threshold requirement of the MN varies due to this probability of handover is estimated at different threshold based on the no. of networks. For five networks at threshold $\left(\mathrm{G}_{\mathrm{th}}\right)=11$, traffic load $(\beta)=8$ the probability of handover is 0.87652543 and for the threshold $\left(\mathrm{G}_{\mathrm{th}}\right)=15$, traffic load $(\beta)=8$ the probability of handover is 0.64373022 . For two networks at threshold $\left(\mathrm{G}_{\mathrm{th}}\right)=0$, traffic load $(\beta)=8$, the probability of handover is 0.56670640 and for the threshold $\left(\mathrm{G}_{\mathrm{th}}\right)=4$, traffic load $(\beta)=8$ the probability of handover is 0.19427733.It is observed that the probability of handover decreases with increase in threshold. 


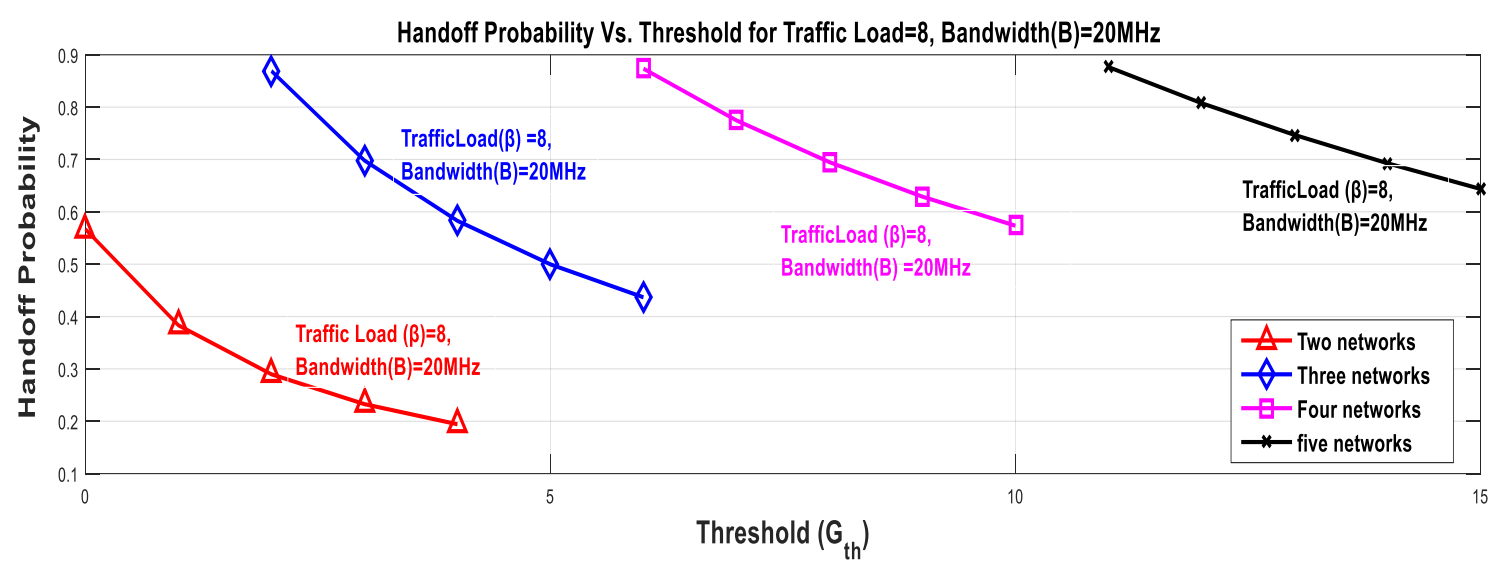

Figure 3. Probability of handover (PH) vs Threshold $\left(\mathrm{G}_{\mathrm{th}}\right)$ for different Traffic load $(\beta)$ and different networks at bandwidth $(\mathrm{B})=20 \mathrm{MHz}$

Table 2. Probability of handover $(\mathrm{PH})$ vs threshold $\left(\mathrm{G}_{\mathrm{th}}\right)$ for different Traffic load $(\beta)$ and for different networks at bandwidth $(\mathrm{B})=20 \mathrm{MHz}$

\begin{tabular}{|c|c|c|c|c|c|c|c|c|}
\hline $\begin{array}{l}\text { S. } \\
\text { No }\end{array}$ & $\begin{array}{l}\text { Threshold } \\
\quad\left(\mathrm{G}_{\mathrm{th}}\right)\end{array}$ & $\begin{array}{c}\text { For two } \\
\text { networks } \\
\text { Probability of } \\
\text { handover (PH) } \\
\text { At traffic } \\
\text { load=8 }\end{array}$ & $\begin{array}{l}\text { Threshold } \\
\qquad\left(\mathrm{G}_{\mathrm{th}}\right)\end{array}$ & $\begin{array}{c}\text { For three } \\
\text { networks } \\
\text { Probability of } \\
\text { handover (PH) } \\
\text { At traffic } \\
\text { load=8 }\end{array}$ & $\begin{array}{l}\text { Threshold } \\
\left(\mathrm{G}_{\mathrm{th}}\right)\end{array}$ & $\begin{array}{c}\text { For four } \\
\text { networks } \\
\text { Probability of } \\
\text { handover } \\
\text { (PH) At } \\
\text { traffic load=8 }\end{array}$ & $\begin{array}{l}\text { Threshold } \\
\quad\left(\mathrm{G}_{\mathrm{th}}\right)\end{array}$ & $\begin{array}{c}\text { For five } \\
\text { networks } \\
\text { Probability of } \\
\text { handover } \\
(\mathrm{PH}) \mathrm{At} \\
\text { traffic load=8 }\end{array}$ \\
\hline 1 & 0 & 0.56670640 & 2 & 0.86903007 & 6 & 0.87344363 & 11 & 0.87652543 \\
\hline 2 & 1 & 0.38326154 & 3 & 0.69810749 & 7 & 0.77464731 & 12 & 0.80763668 \\
\hline 5 & 4 & 0.19427733 & 6 & 0.43672182 & 10 & 0.57346427 & 15 & 0.64373022 \\
\hline
\end{tabular}

\subsection{Probability of handover vs. bandwidth}

Figure 4 and Table 3 represents the variation of probability of handover with respect to bandwidth for different threshold values, here the traffic load is fixed at 8 . For five networks for a fixed threshold $\left(G_{t h}\right)=11$, at the traffic load $(\beta)=8$, the probability of handover is 0.76923077 at the bandwidth $=12$ and at bandwidth $=20$ the probability of handover is 0.0 .87652543 . It is noticed that similarly for two, three and four networks, at fixed threshold value of corresponding network and traffic load, the probability of handover slightly increases with increase in bandwidth.

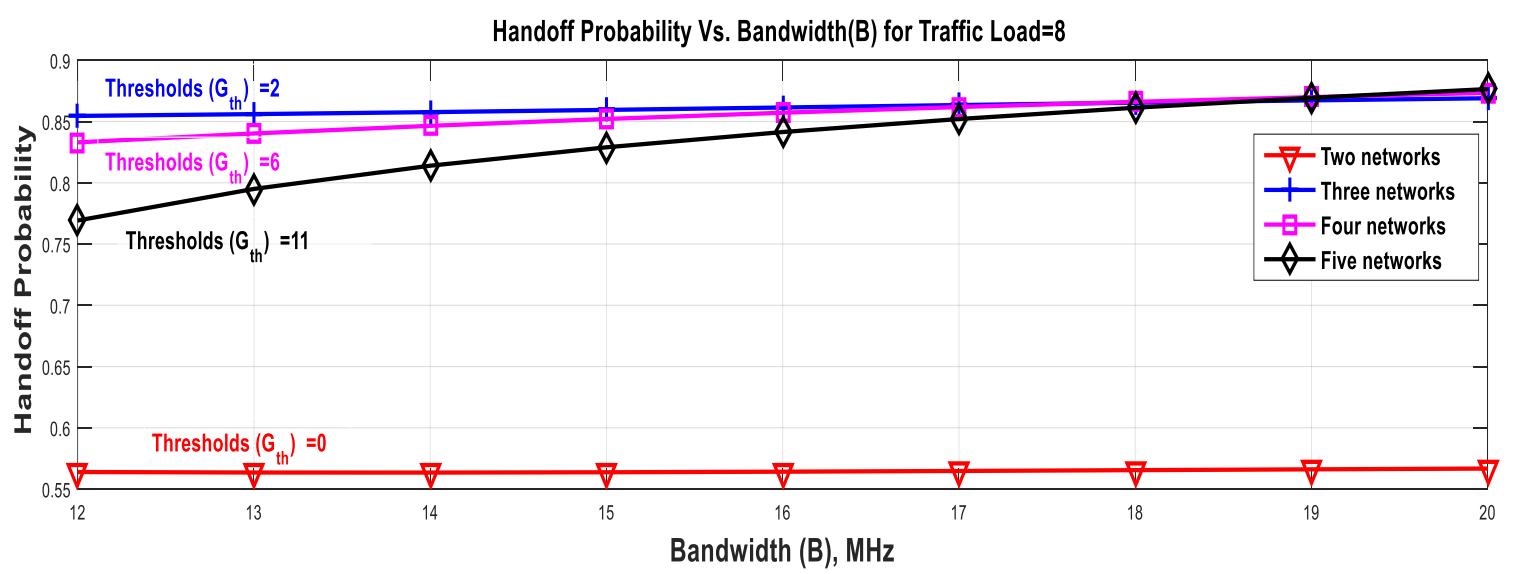

Figure 4. Probability of handover $(\mathrm{PH})$ vs bandwidth (B) for different traffic load $(\beta)$ and different networks at constant Threshold $\left(\mathrm{G}_{\mathrm{th}}\right)$ 
Table 3. Probability of handover (PH) vs bandwidth (B) for constant threshold $(\mathrm{Gth})=9,10,11$

\begin{tabular}{cccccc}
\multicolumn{7}{c}{ at traffic load $\left(_{\beta}\right)=8$} \\
\hline S.No & $\begin{array}{c}\text { Bandwidth } \\
(\mathrm{B}) \text { in } \mathrm{MHz}\end{array}$ & $\begin{array}{c}\text { For two networks } \\
\text { Probability of } \\
\text { handover }(\mathrm{PH}) \text { at } \\
\text { traffic load=8 and } \\
\text { threshold }\left(\mathrm{G}_{\mathrm{th}}\right)=0\end{array}$ & $\begin{array}{c}\text { For three networks } \\
\text { Probability of } \\
\text { handover }(\mathrm{PH}) \text { at } \\
\text { traffic load=8 and } \\
\text { threshold }\left(\mathrm{G}_{\mathrm{th}}\right)=2\end{array}$ & $\begin{array}{c}\text { For four networks } \\
\text { Probability of } \\
\text { handover }(\mathrm{PH}) \text { at } \\
\text { traffic load=8 and } \\
\text { threshold }\left(\mathrm{G}_{\mathrm{th}}\right)=6\end{array}$ & $\begin{array}{c}\text { For five networks } \\
\text { Probability of } \\
\text { handover }(\mathrm{PH}) \text { at } \\
\text { traffic load=8 and } \\
\text { threshold }\left(\mathrm{G}_{\mathrm{th}}\right)=11\end{array}$ \\
\hline 1 & 12 & 0.56388746 & 0.85460295 & 0.83301954 & 0.76923077 \\
2 & 13 & 0.56348267 & 0.85607649 & 0.84025611 & 0.79500828 \\
3 & 14 & 0.56342790 & 0.85770180 & 0.84651547 & 0.81395807 \\
4 & 15 & 0.56367934 & 0.85951826 & 0.85211401 & 0.82898660 \\
5 & 16 & 0.56415128 & 0.86146988 & 0.85720827 & 0.84144932 \\
6 & 17 & 0.56475268 & 0.86346663 & 0.86186396 & 0.85207743 \\
7 & 18 & 0.56540915 & 0.86542588 & 0.86610833 & 0.86129940 \\
8 & 19 & 0.56607010 & 0.86729048 & 0.86996047 & 0.86938645 \\
9 & 20 & 0.56670640 & 0.86903007 & 0.87344363 & 0.87652543 \\
\hline
\end{tabular}

\section{CONCLUSION}

In this paper, the mathematical model of probability of handover for multiple heterogeneous networks is developed. The analysis is carried out by comparing the probability of handover of multiple heterogeneous wireless networks in terms of probability of handover vs. traffic load, probability of handover vs. threshold and probability of handover vs. bandwidth. From the results, it is observed that increase in traffic load with fixed threshold there is no much variation in probability of handover and also observed that with increase in threshold the probability of handover is decreased. Further, it is also observed that for multiple HetNets, at fixed traffic load, the probability of handover increases with the increase in number of networks at different threshold values.The proposed probability of hadover analysis is further helpful for minimizing the wrong decision handover probabilities in practical HetNets such as integration of LTE, Wi-Fi and WiMAX etc. for improving their QoS.

\section{ACKNOWLEDGEMENTS}

This work was supported under Early Career Research Award by the SERB, Department of Science and Technology (DST), New Delhi, India (Grant no: ECR/2016/001804 dated: 13-FEB-2017). The authors would like to thank the management for encouraging towards research environment.

\section{REFERENCES}

[1] S. Bhosale and R. Daruwala., "Multi-criteria Vertical Handoff Decision Algorithm Using Hierarchy Modeling and Additive Weighting in an Integrated WLAN/WiMAX/UMTS Environment-A Case Study," KSII Transactions on Internet \& Information Systems, vol. 8, 2014.

[2] E. Gustafsson and A Jonsson, Ericsson Research., "Always Best Connected," IEEE Wireless Communications, vol. 10, pp. 49-55, 2003.

[3] B. Ma, et al., "Modeling and Analysis for Vertical Handoff Based on the Decision Tree in a Heterogeneous Vehicle Network," IEEE Access, vol. 5, pp. 8812-8824, 2017.

[4] S. Neeraja and G. S. Rao, "A Comparative study on Handoff Algorithms for GSM and CDMA Cellular Networks," International Journal of Electrical and Computer Engineering (IJECE), vol. 7, pp. 1219-1227, 2011.

[5] S. Neeraja, et al., "Analysis of Adaptive Hysteresis Based Horizontal Handoff Algorithm for GSM," International Journal of Innovative Research in Electrical, Electronics, Instrumentation and Control Engineering, vol. 1, pp. 433-437, 2013.

[6] R. S. Chang and S. J. Leu, "Handoff Ordering Using Signal Strength for Multimedia Communications in Wireless Networks," IEEE Transactions on Wireless Communications, vol. 3, pp. 1526-1532, 2004.

[7] K. Yang, et al., "Multi-Dimensional Adaptive SINR Based Vertical Handoff for Heterogeneous Wireless Networks," IEEE Communications Letters, vol. 12, pp. 438-440, 2008.

[8] F. Zhu and J. McNair, "Optimizations for Vertical Handoff Decision Algorithms," IEEE Wireless Communications and Networking Conference, pp. 867-872, 2004.

[9] D. He, et al., "A Simple and Robust Vertical Handoff Algorithm for HeterogeneousWireless Mobile Networks," Wireless Personal Communications, vol. 59, pp. 361-373, 2011.

[10] C. Chi, et al., "Modeling and Analysis of Handover Algorithms," IEEE Global Telecommunications Conference, pp. 4473-4477, 2007

[11] S. Neeraja and G. S. Rao, "Performance Analysis of Bandwidth Based Handoff Algorithm for 4G Heterogeneous Wireless Networks Based On WDHOP," ARPN Journal of Engineering and Applied Sciences, vol. 12, pp. 96-106, 2017. 


\section{BIOGRAPHIES OF AUTHORS}

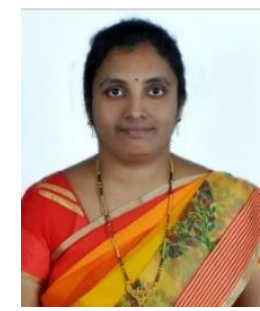

S. Neeraja, she is presently working as a Assistant Professor in the Department of Electronics and Communications Engineering, GITAM (Deemed to be University). She received Ph. D degree from Andhra university in the year 2013. She has over 13 years of Teaching Experience. She has published more than 30 research papers in various reputed International/National journals/Conferences. Her area of Interest is Wireless and Mobile Communications, Wireless Sensor Networks and CDMA/MIMO/OFDMA Wireless Communications. Currently, she is handling a DST-SERB research project.

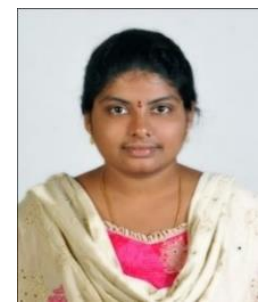

A. Abhishiktha, she is presently working as a JRF in the Department of Electronics and Communications Engineering, GITAM (Deemed to be University) under DST-SERB research project. She has received the B. Tech degree from Vignan Nirula Engineering College and M.E from ANITS Engineering College. Her areas of interests are Wireless Communications and Wireless Sensor Networks. 